\title{
EXPERIMENTAL MEASUREMENTS OF HEAT TRANSFER FROM AN ICED SURFACE OURING ARTIFICIAL AND NATURAL CLOUD ICING CONOITIONS\#
}

\author{
Mark S. Kirby ${ }^{+}$and R. John Hansman, Jr. * \\ Massachusetts Institute of Technology \\ Cambridge, Mass.
}

\section{ABSTRACT}

The heat transfer behavior of accreting ice surfaces in natural (flight test) and simulated (wind tunnel) cloud icing conditions have been studied. Observations of wet and dry ice growth regimes as measured by ultrasonic pulse-echo techniques were made. Observed wet and dry ice growth regimes at the stagnation point of a cylinder were compared with those predicted using a quasi steady-state heat balance model. A series of heat transfer coefficients were employed by the model to infer the local heat transfer behavior of the actual ice surfaces. The heat transfer in the stagnation region was generally inferred to be higher in wind tunnel icing tests than in natural, flight, icing conditions.

\section{NOMENCLATURE}

$\begin{array}{ll}A, B & \text { experimentally derived constants }(-) \\ C_{j} & \text { specific heat capacity of ice }(\mathrm{J} / \mathrm{kg} \mathrm{K}) \\ C_{D} & \text { specific heat capacity of air }(\mathrm{J} / \mathrm{kg} \mathrm{K}) \\ C^{p} & \text { specific heat capacity of water }(\mathrm{J} / \mathrm{kg} \mathrm{K}) \\ D^{W} & \text { Diffusion coefficient of water vapor in } \\ & \text { air }(\mathrm{m} / 2 / \mathrm{s})\end{array}$

d cylinder diameter $(\mathrm{m})$

$h$ local convective heat transfer coefficient $\left(\mathrm{W} / \mathrm{m}^{2} \mathrm{k}\right)$

$k$ thermal conductivity of air (W/m K)

$\mathrm{L}_{f} \quad$ latent heat of fusion of water $(\mathrm{J} / \mathrm{kg})$

$\mathrm{L}_{\mathrm{s}} \quad$ latent heat of sublimation of water $(\mathrm{J} / \mathrm{kg})$

$L_{v} \quad$ latent heat of vaporization of water

(J/kg)

$\dot{M}$ "local mass flux/time $\left(\mathrm{kg} / \mathrm{m}^{2} \mathrm{~s}\right)$

Nu Nusselt number ( $(-)$

Q" local heat flux/time. $\left(\mathrm{W} / \mathrm{m}^{2}\right)$

Re Reynolds number based on cylinder dia. and $V_{\infty}(-)$

$r$ recovery factor, $0.875(-)$

LT cloud supercooling $=-T_{\infty}\left({ }^{\circ} \mathrm{C}\right)$

$T_{\text {surf }}^{\infty}$ equilibrium surface temperature $\left({ }^{\circ} \mathrm{C}\right)$

$\mathrm{T}_{\infty}^{\text {surf }}$ cloud temperature $\left({ }^{\circ} \mathrm{C}\right)$

$t^{\infty} \quad$ icing time ( $s$ )

$V_{\infty} \quad$ freestream velocity $(\mathrm{m} / \mathrm{s})$

$W^{\infty} \quad$ cloud liquid water content $\left(g / \mathrm{m}^{3}\right)$

\& local collection efficiency $(-)$

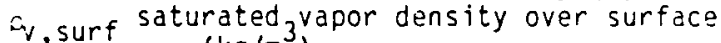
$\left(\mathrm{kg} / \mathrm{m}^{3}\right)$ $\rho_{v, \infty} \quad \begin{gathered}\text { saturated } \\ \left(\mathrm{kg} / \mathrm{m}^{3}\right)\end{gathered}$

+ Research Assistant, Aeronautics and Astronautics

* Assistant Professor, Aeronautics and Astronautics.

\# AIAA Paper 86-1352. Copyright (C) 1986 by MIT.

\section{INTRODUCTION}

Whenever an aircraft encounters liquid moisture in the form of supercooled cloud droplets, or freezing rain, ice will form on the exposed surfaces. Typical cloud droplet diameters range from as large as 50 microns to less than 10 microns. In the case of freezing rain, droplets may be several $\mathrm{mm}$ in diameter. The shape of the accreted ice and its affect on the aircraft's aerodynamic performance depend on several parameters - the cloud temperature, the average cloud droplet size and size spectrum, the amount of liquid water per unit volume, $W$, contained in the cloud and the size, shape and speed of the accreting surface.

RIME ICE

"Cold" cloud temps. $\left(-10^{\circ} \mathrm{C}\right.$ to $\left.-30^{\circ} \mathrm{C}\right)$ Small oroplets $(12 \mu$ typ.)
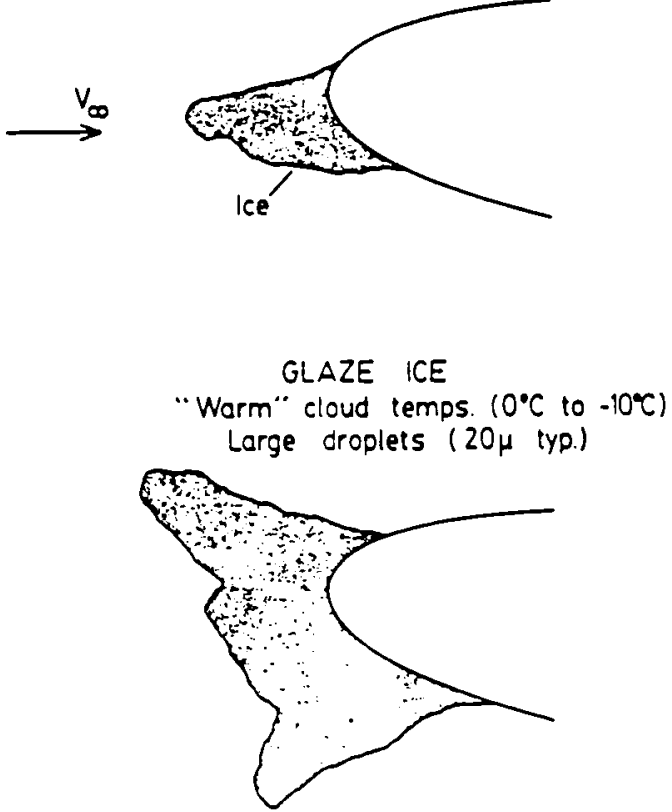

Figure 1. Typical "rime" and "glaze" ice shapes.

When all of the impinging droplets freeze on impact with the accreting surface the ice accretion is characterized as rime ice. The resulting ice shape typically protrudes forward into the airstream (see figure 1). Relatively cold cloud temperatures (below $-10^{\circ} \mathrm{C}$ ) and small droplet sizes promote rime ice formations. At warmer cloud temperatures and for the characteristically larger droplet sizes and 1 iquid water contents present in these clouds, the impinging droplets do not freeze on impact and may run back over the accreting surface as 
liquid water before freezing further downstream on the surface. This type of ice accretion is characterized as glaze ice and often the resulting ice shape displays two pronounced growth peaks, or horns, on either side of the stagnation line(see figure 1 also). The most severe aircraft performance degradation due to ic ing ${ }_{2}$ is typically associated with glaze ice formations ${ }^{2}$.

Figyre 2 illustrates schematically how recent attempts ${ }^{-5}$ to analytically model aircraft icing have decomposed the ice accretion process. First, the aerodynamic flowfield around the body of interest is calculated, usually by an inviscid panelling method. Droplet trajectories around the body are then calculated by integrating the droplet equations of motion within the body flowfield. From these trajectory calculations the mass flux of impinging droplets at a given location on the body can then be determined. The third, and crucial step, involves a thermodynamic analysis of the freezing process at the icing surface. A steady-state energy balance involving the impinging heat load from the droplets and the heat removed by convection, evaporation and sublimation is typically applied to small control volumes along the icing surface. The fourth step then calculates the amount of ice formed at each location on the body as a result of satisfying this energy balance and constructs the ice shape on the body. This entire process may then be repeated using the iced geometry as input for the flowfield calculation. Due to this form of time-stepped solution, any errors or inaccuracies in each of these four steps tend to propagate and may result in an unreafistic ice shape.

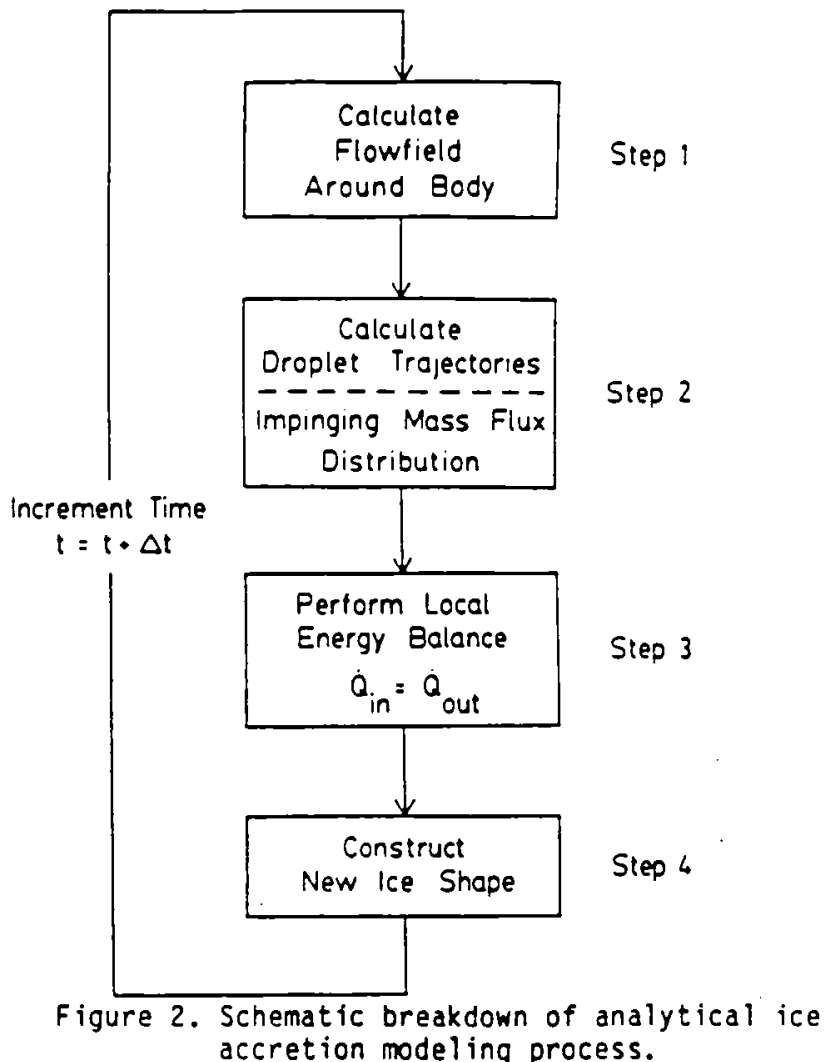

Experimental results ${ }^{6-8}$ have confirmed the accuracy of the flowfield and droplet trajectory calculations. For rime ice growth, where the droplets freeze at the point of impact, the predicted ice shapes are in good agreement with experimentally measured ice shapes. However, for glaze ice conditions the predicted ice shapes are extremely sensitive to the assumed convective heat transfer coefficient distribution over the body, and, to date, no analytic model has accurately predicted ice shapes throughout this important icing regime.

Because of the sensitivity to heat transfer, experimental measurements of the heat transfer coefficient distribution over an iced surface are critical for validating these analytic models. Due to experimental difficulties associated with these measurements on actual ice surfaces, local heat transfer coefficient measurements have only been made ground wooden or foam models of typical ice shapes. In addition, experimental measurements comparing local heat transfer coefficients obtained in icing wind tunnels and in flight are essential if natural icing conditions are to be accurately simulated in icing wind tunnels. Very little experimental data exists in this area.

This paper outlines the steady-state energy balance for the stagnation region of a body. From this energy balance the condition for transition from rime or "dry" ice growth to glaze or "wet" ice growth is determined in terms of the locally impinging mass flux and the local heat transfer coefficient. By measuring the locally impinging mass flux and whether the accreting ice surface is wet or dry, it is thus possible to infer limits on the magnitude of the heat transfer coefficient at the ice surface.

The detection of liquid water on an accreting ice surface is made by a unique application of an ultrasonic pulse-echo technique and is described. Results of tests employing this ultrasonic technique for cylinders exposed to artificial icing conditions in the NASA Lewis Icing Research Tunnel (IRT) and natural icing conditions in flight from the NASA Lewis Twin Otter Icing Research Aircraft are then presented. These experimental results are us?d to compare local heat transfer coefficients mecsured around a bare cylinder with different levels of freestream turbulence and surface roughness.

STEADY-STATE THERMOOYNAMIC MOOEL FOR AN ICING SURFACE

The thermodynamic anaiysis presented in this paper for a surface accreting ice follows the earlier work of Messinger and others 11,12 . Figure 3 shows the principle modes of energy transfer associated with an icing surface. Heat is added to the surface primarily due to the latent heat of fusion released as the droplets freeze, but also from aerodynamic heating and, to an even smaller extent, from the kinetic energy of the droplets impacting the surface. Heat is removed from the surface primarily by convection, and to a lesser degree by sublimation (when the surface is dry) or evaporation (when the surface is wet). In addition, heat is absorbed from the surface as the supercooled droplets impinge and warm to $0^{\circ} \mathrm{C}$. 


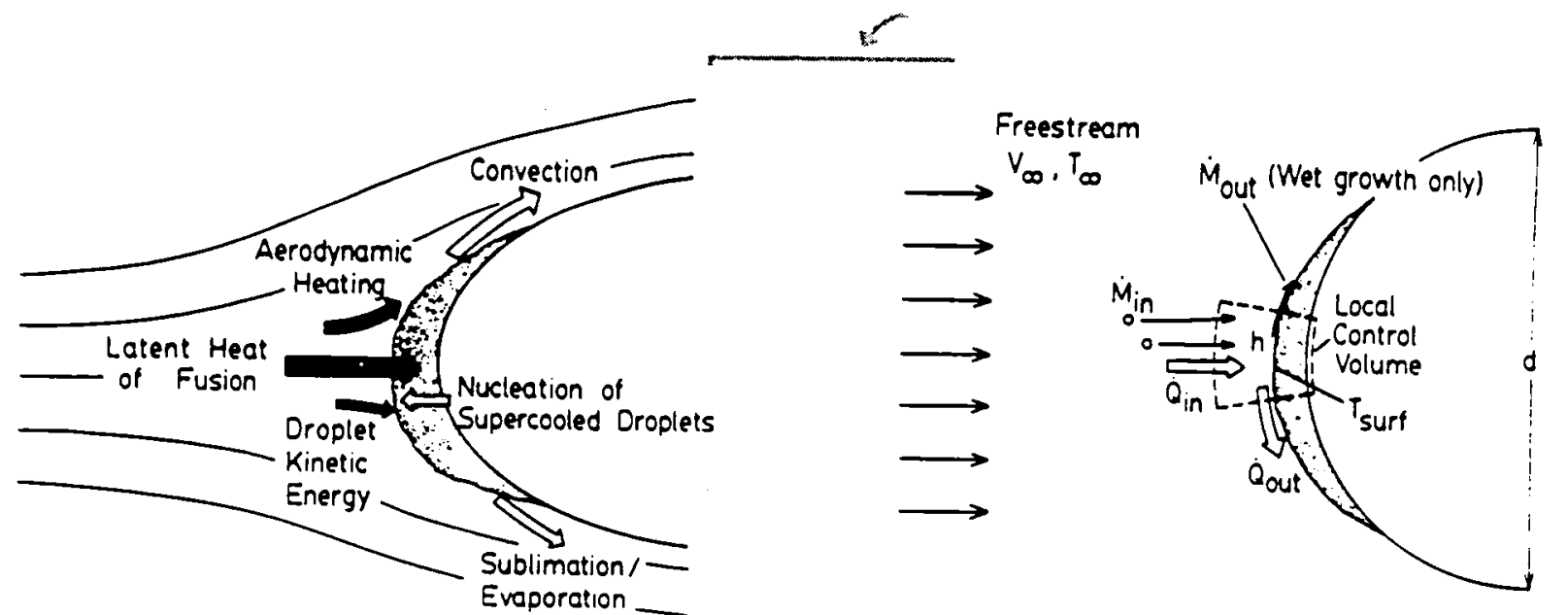

Figure 3. Modes of energy transfer for an accreting ice surface.

Figure 4 depicts the local control volume examined in this analysis. Since only the stagnation region of the body is considered in this paper, it is assumed that the only liquid entering the control volume is due to the impinging droplets. Liquid may, however, flow out of the control volume along the ice surface. Thus if the ice surface in the stagnation region is wet, insufficient heat is being removed to freeze all of the impinging liquid, and therefore the "freezing fraction", $n$, is less than unity, where $n$ is given by

$$
n=\frac{\dot{M}_{\text {frozen }}^{\prime \prime}}{\dot{M}_{\text {impinging }}^{\prime \prime}}
$$

When the ice surface is dry the freezing fraction is unity. The steady-state assumption requires that the rate at which energy is added to the control volume equals the rate at which it is removed, i.e.

$$
\text { Q" }{ }_{\text {IN }}=\text { Q" OUT }^{\prime}
$$

At steady-state it is assumed that the ice surface achieves a locally uniform equilibrium temperature, $T_{\text {surf. }}$ Conduction into the ice is assumed to be zero and chordwise conduction between adjacent control volume is neglected. With these assumptions eq. (1) may be written in terms of its component heat terms as

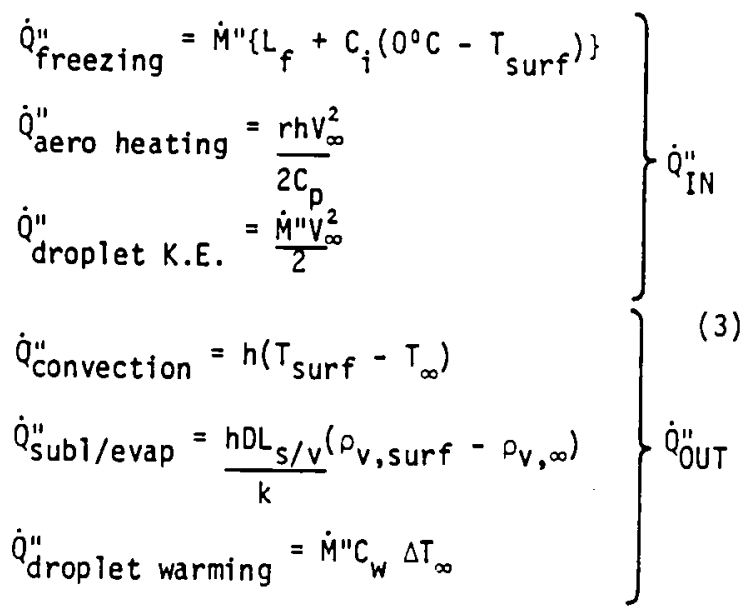

Figure 4. Stagnation region control volume used for steady state thermodynamic analysis.

$$
\begin{aligned}
& \dot{M}^{\prime \prime}\left\{L_{f}+\frac{v_{\infty}^{2}}{2}+C_{j}\left(0^{0} C-T_{s u r f}\right)\right\}+\frac{r h v_{\infty}^{2}}{2 C_{p}}= \\
& h\left\{\left(T_{\text {surf }}-T_{\infty}\right)+D L_{s}\left(\rho_{v, s u r f}-\rho_{v, \infty}\right)\right\}+\dot{M}^{\prime \prime} C_{W} \Delta T_{\infty}
\end{aligned}
$$

Note that this equation (eq. 4) assumes all of the impinging mass flux, $\dot{M}^{\prime \prime}$, is frozen, thus the ice surface is dry and the latent heat of sublimation, $L_{\text {, }}$ is used in the mass transfer term from the sứrface.

The ice surface will first start to become wet when the equilibrium temperature of the surface rises to $0^{\circ} \mathrm{C}$. The energy balance appropriate for the transition between dry and wet growth is thus

$$
\begin{gathered}
\dot{M}^{\prime \prime}\left\{L_{f}+\frac{\left.v_{\infty}^{2}\right\}}{\overline{2}}+\frac{r h v_{\infty}^{2}}{2 C_{p}}=h\left(\left(0^{\circ} \mathrm{C}-T_{\infty}\right)+\right.\right. \\
\left.\frac{D v_{v}}{k}\left(\rho, 0^{0} c^{-\rho} v_{, \infty}\right)\right\}+\dot{M}^{\prime \prime} C_{w} \Delta T_{\infty}
\end{gathered}
$$

In this case the freezing fraction must be very slightly.less than unity, since the surface is now wet, although it has been taken to be unity for this transitional case. The latent heat of vaporization, $L_{V}$, is however used to represent the evaporative cooling term.

The local mass flux, $\dot{M} "$, of droplets impinging on a body is given by

$$
\dot{M} "=\beta W V_{\infty}
$$

Where $\beta$ is the "local collaction efficiency" and is defined as the ratio of the locally impinging mass flux to the freestream mass flux, i.e.

$$
\beta=\frac{\text { Locally Impinging Droplet Flux }}{\text { Freestream Droplet Flux }}
$$

The local collection efficiency is governed by the ratio of the impinging droplets inertia to the aerodynamic drag on them due to the freestream flowfield disturbance created by the body. For most aircraft icing regimes the local collection efficiency is primarily a function of the cloud droplet median volume diameter, MVD, and the size 
of the accreting body. Typical values for the local collection efficiency on the stagnation line of a $10 \mathrm{~cm}$ diameter (4") cylinder at a freestream airspeed of $100 \mathrm{~m} / \mathrm{s}(230 \mathrm{mph})$ are 0.6 for a cloud composed of droplets 20 microns in diameter and 0.4 for a cloud of 12 micron droplets. Thus a small body moving rapidly through a cloud of large droplets will have a much higher local collection efficiency than a large body moving slowly through a cloud of small droplets. Using eq. 6 allows the critical condition for transition between wet and dry ice growth to be expressed as

$$
\begin{gathered}
\Delta W V_{\infty}\left\{L_{f}+\frac{\left.V_{\infty}^{2}\right\}}{2}+\frac{r h V_{\infty}^{2}}{2 C_{p}}=h\left(\left(0^{\circ} C-T_{\infty}\right)+\right.\right. \\
\frac{D L_{v}}{k}\left(\rho_{v, 0^{\circ} C^{-\rho} v, \infty}\right)+B N V_{\infty} C_{w} \Delta T_{\infty}
\end{gathered}
$$

It is convenient to express the convective heat transfer coefficient, $h$, in terms of the dimensionless Nusselt number, $\mathrm{Nu}$, where

$$
\mathrm{Nu}=\frac{\mathrm{hd}}{\mathrm{k}}
$$

With $d$ being the uniced diameter or characteristic dimension of the body, and $k$ the thermal conductivity of air. Experimental measurements of local heat transfer coefficient distributions are often presented in terms of a power law relationship between the Nusselt number and the Reynolds number,

$$
N u=A R e^{B}=A\left(\frac{\rho_{\infty} V_{\infty} d}{\mu_{\infty}}\right)^{B}
$$

Where $A$ and $B$ are experimentally derived constants. Using eqs. 9 and 10 , equation 8 may be rewritten in terms of a "critical" impinging 1 iquid water content, $\mathrm{EW}$ (eq(11) below). Here the product $(B W)$ is the wet/dry threshold and represents the crifleal locally impinging 1 iquid water content (gramms/meter ${ }^{3}$ ) necessary to produce a wet ice surface. If $\mathrm{BW}$ is greater than this critical value the ice surface will be wet and the freezing fraction will be less than one, while if $B W$ is less than this critical value the ice surface will be dry. From this equation it can be seen that $(B W)$ depends on the assumed values of $A$ and $B$ in Ehe heat transfer coefficient model. By measuring the locally impinging liquid water content, $B W$, and whether the resulting ice growth is wet or dry it is thus possible to compare different heat transfer models (different $A$ and $B$ constants in eq. 10) and determine which models best predict the observed wet or dry ice growth. The technique used to detect the presence or absence of liquid water on an accreting ice surface is described in the next section.
ULTRASONIC PULSE-ECHO ANALYSIS OF AN ACCRETING ICE SURFACE

Figure 5 illustrates the principle of the ultrasonic pulse-echo measureqęnt technique applied for an icing surface. ${ }^{3}$ A small transducer mounted flush with the accreting surface emits a brief compressional wave, the ultrasonic "pulse", that travels through the ice as shown. This wave is reflected at the ice surface and returns to the emitting transducer as an echo signal. By measuring the time elapsed between the emission of the pulse and the return of the echo, the ice thickness over the transducer may be calculated using the appropriate speed of sound for ice. By repeatedly emitting pulses the ice thickness can be constantly measured as ice accretes on the body; pulses are typically emitted several thousand times a second, while the time elapsed between pulse emission and echo return is on the order of microseconds for ice thicknesses less than $5 \mathrm{~cm}\left(2^{\prime \prime}\right)$.
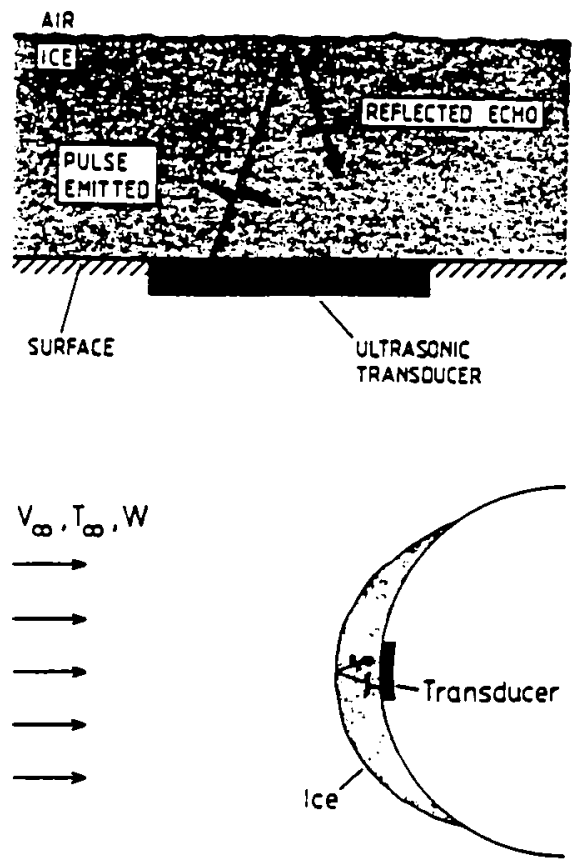

Figure 5. Ultrasonic pulse-echo measurement technique.

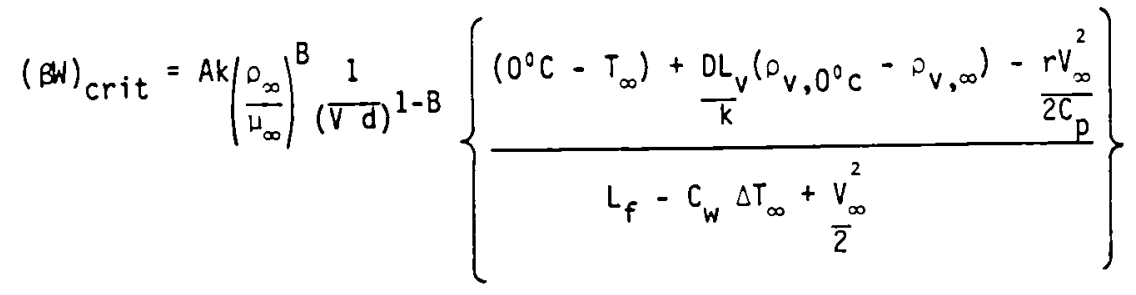


In addition to obtaining the ice thickness from the pulse-echo transit time, the condition of the ice surface may also be monitored via the characteristics of the uitrasonic echo pattern received from the ice surface. Specifically it. has been found that the echo patterns received from a dry ice surface and a wet ice surface are markedly different. A "single" echo, corresponding to the ice/air interface over the transducer, is received from a dry ice surface. However during wet ice growth the presence of liquid water on the ice surface creates a different, reflective interface, namely that between liquid and air. Thus during wet ice growth the received echo pattern contains an echo from the ice/water interface and further, rapidly varying echoes from the water/air interface. The presence of these echoes, which vary due to the distortion of the water by the impinging droplets and flowfield, is used to determine if the ice growth is wet. If only a single echo is received from the ice surface then the ice growth is determined to be dry.

\section{EXPERIMENTAL FACILITIES ANO TEST DESCRIPTION}

\section{Icing Research Tunnel Tests}

The first series of tests was performed in the NASA Lewis Research Center Icing Research Tunne1. A $0.102 \mathrm{~m}\left(4.0^{\prime \prime}\right)$ diameter cylinder instrumented with ultrasonic transducers was suspended vertically from the icing tunnel roof as shown in figure 6 . The transducers were located on the stagnation line of the cylinder. The echo signals received from these transducers were

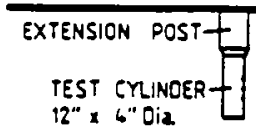

IEING GLOUD
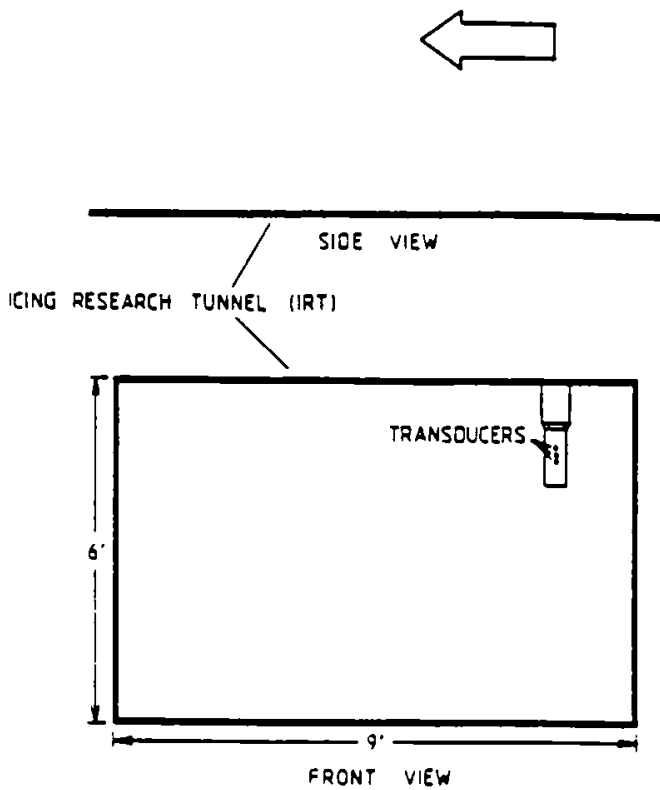

Figure 6. Test cylinder installation for icing wind tunnel (IRT) tests. displayed on an oscilloscope. The oscilloscope screen was video-taped in order to provide a permanent record of the time-dependent echo patterns. The test procedure consisted of lowering the tunnel temperature to the desired icing cloud condition with the water spray off. Once the tunnel temperature had stabilized, the water spray system was turned on in order to produce a cloud of droplets of the desired size (median volume diameter). Typically the spray system was activated for a six minute period, after which it was turned off. Photographic and other measurements of the iced cylinder were then made and the cylinder was completely de-iced before the start of the next run. A total of 36 runs for 15 different icing conditions were performed.

\section{Natural Icing Tests}

A second series of tests was performed in natural icing conditions using a $0.114 \mathrm{~m}$ (4.5") diameter cylinder similarly instrumented with ultrasonic transducers on the stagnation line. An oscilloscope was again used to display the received echo signals and video-taped as before. The cylinder was exposed to the icing cloud via an experiment carrier mounted in the roof of the NASA Lewis Icing Research Aircraft, (De Havilland Twin otter) shown in figure 8 . When deployed, the cylinder was located $0.53 \mathrm{~m}$ (21") into the freestream above the roof-l ine of the aircraft. The cylinder was exposed toroughout the icing encounter, which typically lasted approximately 20 minutes. Throughout the exposure other instruments mounted on the research aircraft measured aircraft and icing cloud parameters. In particular a Johnson-Williams hot-wire probe was used to record cloud liquid water content and a forward scattering laser probe (FSSP) was used to measure the cloud droplet size distribution. Four separate exposures were conducted in this series of flight tests.



Figure 7. Test cylinder installation for natural ic ing flight tests on the NASA, Twin Otter, Icing Research Aircraft. 
Experimental Results \& Discussion

The limited time available for testing in the icing research tunnel and the research aircraft prevented a precise determination of the local heat transfer coefficient by means of the experimentally measured wet or dry ice growths alone. However, the wet/dry ice growth data obtained can be used to compare the ice growth predicted by different heat transfer coefficients in the form $N u=A R e^{3}$ and the quasi steady-state icing model. Recent experimental heat transfer coefficient measurements about a bare cylinder by Van Fossen et al., in support of NASA Lewis' icing research programme are compared in this way. The bare cylinder is considered because most of the wet/dry measurements were obtained for relatively small ice thicknesses, and hence the geometry is essentially that of a bare cylinder. In the van Fossen study heat transfer coefficients were measured for two different freestream turbulence levels, $0.5 \%$ and $3.5 \%$, and for two different cylinder surface conditions, one smooth and one roughened with grains of sand with an average element height of $0.33 \mathrm{~mm}$. The $0.5 \%$ freestream turbulence level was the minimum turbulence level achievable in the Van Fossen tests. The $3.5 \%$ turbulence was chosen to characterize the higher turbulence level believed to exist in the icing research tunnel.

Icing Research Tunnel Results

Figure 8 shows the ultrasonically measured ice growth for six different icing conditions in the icing research tunnel. The freestream velocity was the same, $102.8 \mathrm{~m} / \mathrm{s}(230 \mathrm{mph})$, for all six runs shown. The impinging liquid water content, $B W$, was determined from the ultrasonically measured dry ice growth accretion rate, since when the freezing fraction is unity the local ice accretion rate, $d$, is given by

$$
\dot{d}=\frac{\varepsilon W V_{\infty}}{D_{j c e}}
$$

In all cases the ice density, o be that of the pure substance.

Figure 8 also shows the four wet/dry threshold curves calculated using the Van Fossen heat transfer coefficients. These curves are plotted versus ambient temperature and were calculated for a freestream velocity of $102.8 \mathrm{~m} / \mathrm{s}$ $(230 \mathrm{mph})$, and a cylinder diameter of $0.102 \mathrm{~m}$ (4"). The four curves shown thus represent the transition line between wet and dry ice growth calculated for the four different local heat transfer coefficients implied by the Van Fossen data. If the local impinging liquid water content exceeds this value of (BW) for a given ambient temperature then the ice growth is calculated to be wet, and if $\mathrm{BW}$ is less than (BW) growth is predicted to be dry. From the figure, it can be seen that the heat transfer coefficient that best predicts the experimentally observed pattern of wet and dry ice growth is that measured for the cylinder roughened with sand and at a freestream turbulence level of $3.5 \%$. While dry ice growth was observed at $-23^{\circ} \mathrm{C}\left(-10^{\circ} \mathrm{F}\right)$ and an impinging liquid water content equal to $0.47 \mathrm{~g} / \mathrm{m}^{3}$, the heat transfer coefficients for the $0.5 \%$ freestream turbulence level clearly imply wet growth for these conditions. Thus it appears that the $0.5 \%$ turbulence level heat transfer

\begin{tabular}{|ccc|}
\hline Cylinder Dia. $=0.102 \mathrm{~m}$ \\
Freestream Vel. $=102.8 \mathrm{~m} / \mathrm{s}$ \\
Symbol & $L W C$ & $M V D$ \\
& $\left(g / \mathrm{m}^{3}\right)$ & $(\mu)$ \\
0 & 0.75 & 20 \\
$\Delta$ & 0.37 & 12 \\
\hline
\end{tabular}

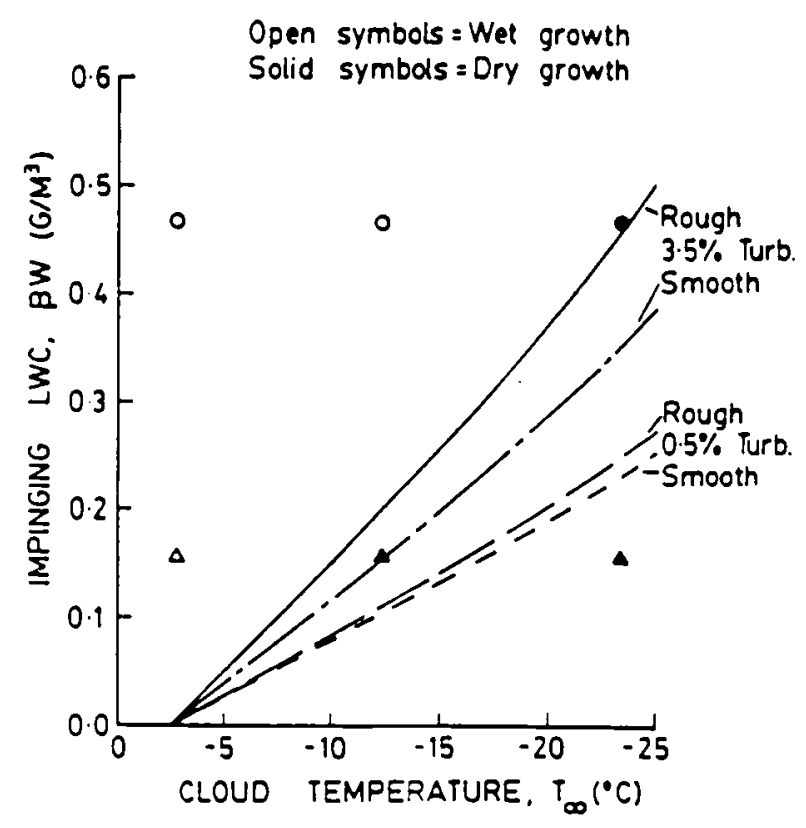

Figure 8. Plot of impinging liquid water content versus cloud temperature showing ultrasonically measured wet/dry ice growth and theoretical wet/dry threshold curves for four different heat transfer coefficients. ( $V_{0}=102.8 \mathrm{~m} / \mathrm{sec}$ (230mph).

coefficients underpredict the actual heat transfer in the icing tunnel are therefore too low.

Since only the stagnation region of the cylinder is considered, the local heat transfer coefficient in this region is less sensitive to the surface roughness than to the freestream turbulence level, as can be seen from the four curves in figure 8 . However local surface roughness does play a critical role in determining where boundary layer transition occurs, and this in turn significantiy affects the heat transfer distribution around the body and therefore the resulting ice shape. Accurate analytic models of the local surface roughness on real iced surfaces have not yet been developed; however the local surface roughness has been found to vary with both position on the body and the icing conditions under which the ice was sormed. For example, a surface roughness of $2 \mathrm{~mm}$ has been measured at $-8^{\circ} \mathrm{C}$ $\left(+18^{\circ} \mathrm{F}\right)$ for ice accreted on a $0.53 \mathrm{~m}$ chord NACA 0012 airfoil, while at $-26^{\circ} \mathrm{C}\left(-15^{\circ} \mathrm{F}\right)$ the surface roughness was found to be less than $0.1 \mathrm{~mm}$. Thus while the heat transfer coefficient implied by the "rough" surface, 3.5\% turbulence level measurements appears to best predict the experimentally observed pattern of wet and dry ice growth, this heat transfer "model" may well only be applicable to the stagnation region and a different model may apply elsewhere on the cylinder. 
A clear understanding of the stagnation region heat transfer is essential for ice shape prediction by current analytic icing models. Since these models assume that all the impinging 1 iquid not frozen in the stagnation region flows downstream into the adjacent control volumes (see fig. 4), errors in the assumed stagnation region heat transfer coefficient will significantly change the mass flux distribution around the body during wet growth. If for example the stagnation region heat transfer coefficient used in such an icing model is less than the actual value, then during wet growth the model will overpredict the amount of liquid running out of the stagnation region into the adjacent control volume. This in turn may erroneously produce further liquid runback from this control volume, when in fact dry growth is the correct condition for this region. The ice shapes predicted in such a case will be in poor agreement with the actually observed shape, particularly when the feedback process inherent in the time-stepped flowfield and droplet trajectory calculations is taken into account (fig. 2).

Since the rough surface, $3.5 \%$ freestream turbulence heat transfer coefficient appeared to best approximate the actual heat transfer occurring in the icing research tunnel (based on the wet/dry ice surface date from the uitrasonic tests), this heat transfer power law model

$$
\mathrm{Nu}=0.2460 \mathrm{Re}^{0.6444}
$$

was compared with other ultrasonic wet/dry ice growth data obtained at different tunnel icing cloud conditions. Figure 9 shows two plots similar to figure 8, with impinging liquid water content plotted versus ambient temperature. Ultrasonic wet/dry ice growth measurements are shown for two freestream velocities, $71.5 \mathrm{~m} / \mathrm{s}$ (160mph) and $49.2 \mathrm{~m} / \mathrm{s}(110 \mathrm{mph})$. The impinging liquid water content, $B W$, was obtained from the dry growth accretion rate, where available, or by calculation of $B$ for those cases where only wet or marginally wet ice growth was observed. The wet/dry threshold curves calculated using the $3.5 \%$ turbulence, rough surface heat transfer coefficient are plotted.

The $3.5 \%$ turbulence level, rough surface heat transfer coefficient correctly predicts all three observed dry ice growth cases. In addition, the two marginally wet cases observed suggest that the heat transfer over the ice surface may in fact be even greater than that implied by the $3.5 \%$ turbulence model. This would be consistent with the experimental results shown in figure 8 where dry growth was observed in one case while the $3.5 \%$ turbulence heat transfer coefficient predicted slightly wet growth.

Based on the results presented in figures 8 and 9 it appears that the heat transfer coefficient model that best approximates the actual heat transfer occuring in the icing research tunnel is the $3.5 \%$ turbulence level, rough surface model. The actual heat transfer coefficient is clearly greater than those applicable at the low $(0.5 \%)$ turbulence level and may be even greater the high (3.5\%) turbulence level value.

\begin{tabular}{ccc|}
\hline Cylinder & Dic. $=0.102 \mathrm{~m}$ \\
Symbol & LWC & MVO \\
& $\left(g / \mathrm{m}^{3}\right)$ & $(\mu)$ \\
0 & 1.05 & 20.5 \\
$\Delta$ & 0.52 & 16 \\
0 & 1.50 & 18 \\
$\nabla$ & 0.75 & 14 \\
\hline
\end{tabular}

Open symbols $=$ Wet growth Solid symbols = Ory growth
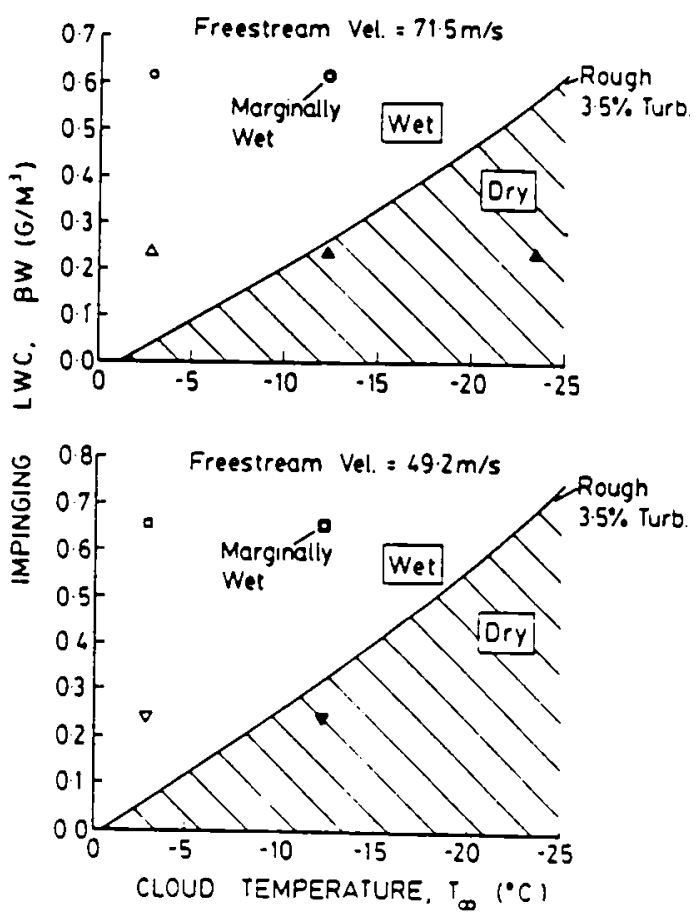

Figure 9. Plot of impinging liquid water content versus cloud temperature showing ultrasonically measured wet/dry ice growth at two additional free stream velocities and the theoretical wet/dry threshold curve for the $3.5 \%$ turbulence level, rough surface, heat transfer coefficient. 
Natural Icing Cloud Test Results

While constant icing conditions were maintained throughout each exposure in the icing research tunnel, the natural icing cloud conditions, most noticeably the liquid water content, were not constant throughout each flight. Figure 10 shows a plot of cloud liquid water content versus exposure time for research flight 85-24. The liquid water content was measured by a Johnson-Williams hot-wire probe located near the nose of the aircraft (see figure 7). Also shown, are the experimentally observed periods of dry, wet and transitional ice growth, produced by the varying impinging liquid water content. The ultrasonic echo patterns received from the accreting ice surface were used to determine if the ice growth was wet, dry or transitional. Ice growth was characterized as transitional when the ultrasonic echoes received from the ice surface displayed neither predominantly dry nor wet echo patterns.

Since the thermodynamic model used to compare heat transfer coefficients assumes a quas $i$ steady-state icing process, and since the cloud 1 iquid water content varied significantly throughout each exposure, a simple, steady-state "time constant" was estimated. This time constant was then applied as a criteria for comparing the ultrasonic data with the wet/dry growth regimes predicted by the steady-state model. A time constant of ten seconds was selected based on the transient thermal response of a thin ice layer and on the time response of the Johnson-Williams

liquid water content measurements. Therefore only liquid water content levels sustained for greater than ten seconds were used in the categorization of ice growth as wet, dry or transitional.

Figure 11 is a plot of impinging liquid water content versus cloud temperature. The experimentally observed ice growth regimes during the four research flights conducted are shown. Note that during flights 85-24 and 85-25 the full range of ice growth regimes was encountered with periods of dry, transitional and wet ice growth observed. No dry ice growth was observed during flights 85-22 and 85-23. Also shown are the four wet/dry threshold curves calculated using the four different Van Fossen heat transfer coefficients (0.5\% turbulence, rough and smooth surface; $3.5 \%$ turbulence, rough and smooth surface). These curves were calculated for the test cylinder diameter of $0.114 \mathrm{~m}(4.5 \% ")$ and for the average (85-22 to $85-25)$ flight airspeed of $71.4 \mathrm{~m} / \mathrm{s}$ (160mph) and the average exposure altitude of $1613 m\left(5292^{\prime}\right)$.

Figures 10 and 11 illustrate the considerable variations encountered in natural icing conditions, both during a particular flight and between flights conducted on different days. For example, the cloud temperature, liquid water content and droplet size were roughly comparable for flights 85-24 and 85-25. However, different ranges of wet and dry ice growth were observed, as indicated by the overlapping experimental wet and dry growth ranges at the same impinging 1 iquid water content. The implication is that the heat transfer differed between the two flights, both at nominally similar icing conditions, but conducted on different days through different clouds.

\author{
Flight $85-24$ \\ Dry = Dry ice growth \\ Wet $=$ Wet ice growth \\ Tr. = Transitional ice growth
}

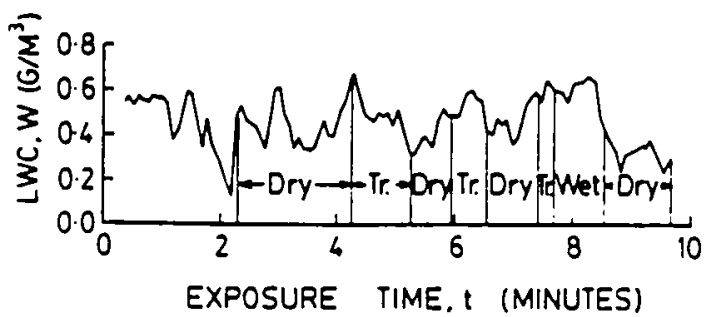

Figure 10. Plot of liquid water content (measured by the Johnson Willitams probe) versus exposure time for flight 85-24 showing typical fluctuations observed in natural icing conditions. Also shown are ultrasonic measured periods of wet, dry, and transitional ice growth.

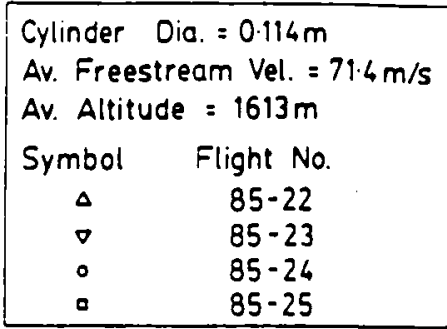

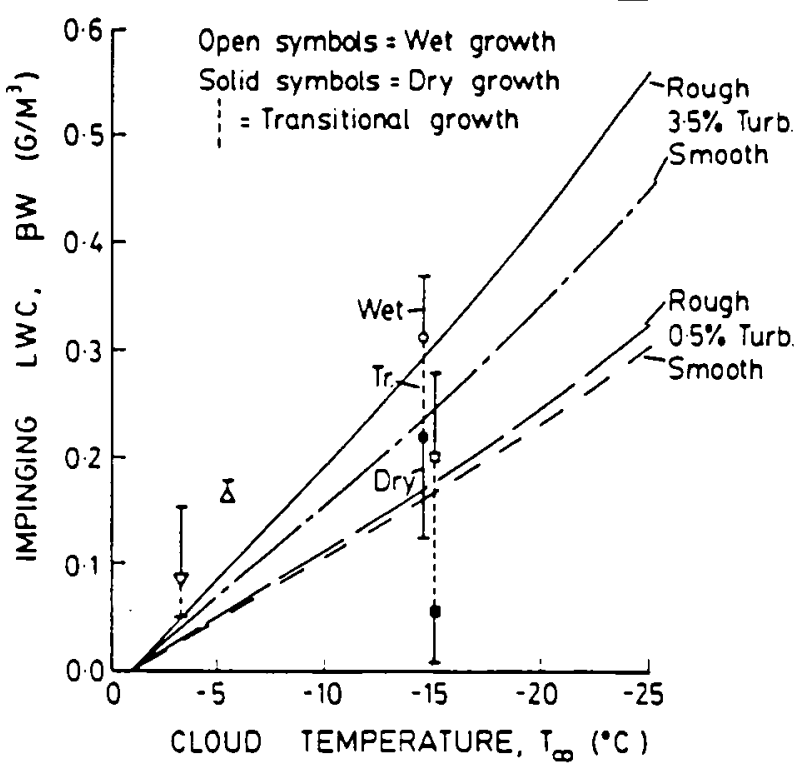

Figure 11. Plot of impinging liquid water content versus cloud temperature showing wet, dry and transitional ice growth regimes observed in flights and theoretical wet/dry threshold curves for four different heat transfer coefficients. 
From the figure it can be seen that for flight $85-25$ the high $(3.5 \%)$ turbulence level heat transfer coefficients overpredict the observed heat transfer, based on the steady-state model analysis. For this flight the low $(0.5 \%)$ turbulence level heat transfer coefficients appear appropriate since both of these coefficients correctly predict the observed wet and dry regimes. The actual turbulence level applicable could be even less than $0.5 \%$ based on the location of the observed wet and dry growth regimes.

The experimentally observed ice growth regimes during flight 85-24 are consistent with the wet/dry threshold predicted by the $3.5 \%$ turbulence level, rough surface heat transfer coefficient. For this flight the low (0.5\%) turbulence level models incorrectly predict wet growth for impinging liquid water content levels where dry growth was experimentally observed. Thus, in contrast to flight $85-25$, the low turbulence level appears to be too low, and the $3.5 \%$ turbulence level model gives acceptable results.

The results of these tests highlight the effect of variations in icing conditions which are inherent in all natural icing encounters. Ice growth may thus vary from wet to dry during a particular encounter as the impinging liquid water content fluctuates. The ice shapes formed during pure dry (rime ice) or pure wet (glaze ice) growth are markedly different (see fig. 1). Therefore the use of an average cloud liquid water content to represent a particular natural icing encounter will in general be inappropriate since this will imply either pure wet or pure dry growth, when in reality the ice growth (wet or dry) varies as a function of time.

The results of the natural icing tests also indicate the heat transfer occurring in natural icing conditions may vary from day to day despite similar icing conditions. One reason for this variation may be due to different icing cloud turbulence levels. Based on the limited amount of flight test data available it appears that in general the appropriate turbulence level for natural icing conditions is somewhat lower than the $3.5 \%$ + level inferred for the icing research tunnel. This result is consistent with previous experimental comparisons befween the icing research tunnel and flight. ${ }^{5}$ For these reasons, care should be taken in extrapolating the results of icing wind tunnel tests to "similar" natural icing cloud conditions.

\section{CONCLUSIONS}

Results of tests conducted in artificial (icing research tunnel) and natural (flight) icing conditions have shown the following;

1. The presence of liquid water on an accreting surface may be detected using an ultrasonic pulse-echo technique.

2. The threshold between dry and wet ice growth can be theoretically determined if the local convective heat transfer coefficient is known.
3. By comparing experimentally measured wet or dry ice growth with wet/dry thresholds predicted by different heat transfer coefficients it is possible to infer heat transfer coefficient values for an iced surface in icing conditions.

4. The heat transfer occurring during initial ice growth in the icing research tunnel appears to be best modelled by Van Fossen's $3.5 \%$ freestream turbulence level, rought surface heat transfer model for a bare cylinder. The actual heat transfer coefficient may be slightly in excess of the values predicted by this model.

5. During natural icing cloud encounters conditions are not constant and as a result periods of wet, dry and transitional ice growth may be observed within a single encounter.

6. The heat transfer occuring during initial ice growth in natural icing conditions has been inferred to vary between that predicted at the $3.5 \%$ Freestream turbulence level and the $0.5 \%$ level, using Van Fossen's data.

7. Oue to variations in natural icing cloud conditions care should be taken in extrapolating results from icing wind tunnels to "similar" natural icing cloud conditions.

\section{ACKNOWLEDGEMENTS}

This work was supported by the National Aeronautics and Space Administration and the Federal Aviation Administration under Grant NGL-22-009-640 and NAG3-666.

\section{REFERENCES}

1. Olsen, W., Shaw, R., and Newton, J. "Ice Shapes and the Resulting Drag Increase for an NACA 0012 Airfoil." NASA TN83556, 1984.

2. Ranaudo, R.J., Mikkelsen, K.L., McKnight, R.C., and Perkins, P.J., Jr., "Performance Degradation of a Typical Twin Engine Commuter Type Aircreft in Measured Natural Icing Conditions," NASA TM-83564, 1984.

3. MacArthur, C.D., Keller, J.L., and Leurs, J.K., "Mathematical Yodeling of Ice Accretions on Airfoils." AIAA-82-0284, January 1982.

4. Lozowski, E.P., Stallabrass, J.R., and Hearty, P.F., "The Icing of an Unheated Non-Rotating Cylinder in Liquid Water Oroplet-Ice Crystal Clouds." National Research Council of Canada (NRC) Report LTR-LT-86, February 1979.

5. Bragg, M.B., Gregorek, G.M., and Shaw, R.J. "Analytical Approach to Airfoil Icing." AIAA-81-0403, January 1981.

6. Brun, R.J. and Mergler, H.W., "Impingement of Water Droplets on a Cylinder in an Incompressible Flow Field and Evaluation of Rotating Multicylinder Method for Measurement of Oroplet-Size Distribution, Volume-Median Droplet Size, and Liquid-Water Content in Clouds", NACA-TN-2904, March 1953. 
7. Gelder, T.F., Smyers, W.H., Jr., and von Glahn, U., "Experimental Droplet Impingement on Several Two-Dimensional Airfoils with Thickness Ratios of 6 to 16 Percent," NACA TN3839, December 1956.

8. Hansman, R.J., "The Effect of the Atmospheric Droplet Size Distribution on Aircraft Ice Accretion," AIAA 84-0108, 1984.

9. Van Fossen, G.J., et.al. "Heat Transfer Distributions Around Nominal Ice Accretion Shapes Formed on a Cylinder in the NASA Lewis Icing Research Tunnel." AIAA-84-0017, January 1982.

10. Messinger, B.L. "Equilibrium Temperature of an Unheated Icing Surface as a Function of Airspeed." Journal of the Aeronautical Sciences, January 1953, pp 24-42.

11. Ludlam, F.H., "The Heat Economy of a Rimed Cyl inder," Quarterly Journal of the Royal Meterological Society, Vol. $77,1951, \mathrm{pp}$ 663-666.

12. Mackl in, W.C., and Payne, G.S., "A Theoretical Study of the Ice Accretion Process," Quarterly Journal of the Royal Meterological Society, Vol. 93, 1967, pp 195-213.

13. Hansman, R.J. and Kirby, M.S., "Measurement of Ice Accretion Using Ultrasonic Pulse-Echo Techniques," Journal of Aircraft, Vol. 22, June 1985, pp. 530-535.

14. Hansman, R.J., and Kirby, M.S., "Real-Time Measurement of Ice Growth During Simulated and Natural Icing Conditions Using Ultrasonic Pulse-Echo Techniques," AIAA 86-0410, 1986.

15. Gelder, T.F., and Lewis, J.P., "Comparison of Heat Transfer from Airfoil in Natural and Simulated Icing Conditions," NACA TN2480, September 1951 . 
OHIO UNIVERSITY 